\title{
Prevalence of HIV in blood donors
}

\author{
Tiwari BR, ${ }^{1}$ Karki S, ${ }^{2}$ Ghimire P, ${ }^{2}$ Yadav P, ${ }^{1}$ Rajkarnikar $M^{1}$ \\ ${ }^{1}$ Central Blood Transfusion Service, Nepal Red Cross Society, ${ }^{2}$ Central Department of Microbiology, Tribhuvan University
}

\section{ABSTRACT}

\begin{abstract}
Background: Nepal is categorized as a country with 'concentrated' epidemic of HIV Nepal Red Cross Society, Blood Transfusion Service has implemented considerable efforts to supply the safe blood and blood products according to the increasing demand. A trend analysis might prove valuable to understand the outcome and appropriately plan for further improvements in providing safe blood supply. The study aimed to assess the trends of HIV seroprevalence over the six years in nationwide and in urbanized setting of Kathmandu Valley.

Methods: This is a retrospective study conducted among Nepalese blood donors through the years 2001-2007. Serum samples were tested using third generation ELISA tests, strictly following the instructions of manufacturers. The donors' information was collected through the donor record register through the respective Blood Transfusion Services.

Results: The overall seroprevalence of HIV among the total blood donors in nation wide and in Central Blood Transfusion Service (CBTS), Kathmandu through the six years of review (from 2001-2007) was 0.33\% and 0.4\% respectively. A significant decreasing trend in HIV seroprevalence was observed both in nationwide and in Central Blood Transfusion Service, Kathmandu $(\mathrm{P}<0.001)$.

Conclusion: The analysis of trends in HIV seroprevalence among blood donors through the year 2001 - 2007 showed a significantly decreasing trend, probably due to the cumulative effect of increasing awareness of HIV and improved screening system for safe blood donation. However, an abrupt increase in demand of blood supply was associated with significant increase in seroprevalence in the year 2005/2006.

Key words: nepalese blood donors, seroprevalence, trends
\end{abstract}

\section{INTRODUCTION}

HIV is the leading global health problem of considerable socioeconomic fatality. The AIDS Epidemic update of 2007 has shown a decrease in global HIV prevalence and it is reported that the seroprevalence of HIV has been leveling off in many countries and is decreasing in Sub-Saharan Africa. ${ }^{1}$ The first case of AIDS in Nepal was reported in $1988 .^{2}$ As of December 2007, National Center for AIDS and STD Control (NCASC) has officially confirmed
10,546 HIV positive cases and 1,610 confirmed cases of AIDS in Nepal. Among the total 10,546 HIV positive cases, $24(0.23 \%)$ cases are described to be associated with blood transfusion or organ transplantation. ${ }^{3}$ UNAIDS has estimated the adult (15-49 years) HIV prevalence rate of $0.5 \%$ by the end of 2005 in general population whereas the number of people living with HIV in the same time has been estimated to be 74,000.4 UN Nepal information platform has reported that over the last few years HIV/AIDS epidemic in Nepal has gained

Correspondence: Mr. Bishnu Raj Tiwari, Central Blood Transfusion Service, Nepal Red Cross Society, Kathmandu, Nepal. Phone: 9841349573, Email: bishnu_117@ yahoo.com 
ground and Nepal has progressed from a low prevalence country to one with 'concentrated' epidemics. ${ }^{5}$ Most of the HIV infections in Nepal have been caused by HIV-1 though recently seroevidence of HIV-2 has been reported from Bhairahava, Nepal. ${ }^{6}$ A situation analysis study of HIV/AIDS has reported that the young people in mobile populations, female sex workers, men who have sex with men, injecting drug users and children as the most vulnerable to HIV/AIDS in Nepal. ${ }^{7}$ Around 10 years ago, Nepal was described as a country having comparatively lower prevalence of HIV/AIDS compared to other countries in Southeast Asia. Seasonal migration to Indian Cities for seeking job and sexual trafficking across a porous Indian border, fuelled by recent political insurgency, has raised Nepal's HIV prevalence second highest in the region after India. ${ }^{8,9}$ So far, the prevalence of HIV among the high risk groups (mobile populations, female commercial sex workers, men who have sex with men, injecting drug users) in Nepal has been reported to be range from $2.3-68 \% .^{10-13}$

This study was conducted to assess the trends in HIV seroprevalence over last six years among Nepalese blood donors population nationwide and in urbanized settings of Kathmandu Valley.

\section{METHODS}

This is a retrospective study conducted in Nepal Red Cross Society, Central Blood Transfusion Service. All blood donors, donating blood through the year 20012007, in Blood Transfusion Services, hospital units or in mobile camps organized all over Nepal were reviewed. Blood donors were informed that their blood would be used for mandatory screening of TTIs but the samples would be tested anonymously and confidentiality would be strictly maintained as per the guidelines of NRCS, BTS. Blood donors were selected for donation according to the criteria of BTS based on National Guidelines for Blood Transfusion Services. Sera from blood donors were tested for detection of Anti HIV1 and 2 antibodies by third generation Enzyme linked Immunosorbent Assay (ELISA) (HIV TRI-DOT Test, J. Mitra and Co, India, Enzygnost Anti HIV $1 / 2$, and Dade Behring, Germany). Initial reactive samples were tested in duplicate. Repeatedly reactive results were considered Seropositive for HIV. The data was entered in Microsoft excel spreadsheet collecting the information through standard records coordinating with regional, district chapter, emergency BTS and hospital units. Statistical analysis including Cochrane- Armitage test for linear trend and multiple pairwise comparisons (Tukey procedure) was performed using the statistical software 'Winpepi ver 3.8'.

\section{RESULTS}

In this retrospective study, 524,328 blood donors in nationwide and 200,673 donors in CBTS were reviewed. The overall seroprevalence of HIV among the total blood donors in the nation wide data was $0.33 \%(95 \%$ $\mathrm{Cl}=0.31-0.34 \%)$. Majority of the donors were males (89.2\%). A statistically significant decreasing trend in HIV seroprevalence was observed through the year 2001/2002-2006/2007 (Cochrane-Armitage test for linear trend, Chi Square $=100.77, \mathrm{P}<0.001$ ) (Table 1). The overall seroprevalence of HIV among the blood donors in CBTS, Kathmandu was $0.4 \%(95 \% \mathrm{Cl}=0.36$ $0.42 \%)$. A statistically significant decreasing trend of HIV seroprevalence was observed among blood donors in CBTS through the year 2001/2002-2006/2007 (CochraneArmitage test for linear trend, Chi Square $=150.8, \mathrm{P}$ $<0.001$ ) (Table 2). The data shows a steadily decreasing trend except in the year 2005/2006, where a significant increase in the seroprevalence rate than in the previous year was observed for both CBTS, Kathmandu and Nationwide HIV trends (Figure 1). The significance in difference of seroprevalence rate in different years was tested by the multiple pairwise comparisons (Tukey procedure) (Table 3).

Table 1. Seroprevalence of HIV among blood donors in the Nationwide data

\begin{tabular}{|llllll|}
\hline Year & Total Donors & Males & Females & HIV Seropositive & Seroprevalence (\%) \\
\hline $2001 / 2002$ & 72,459 & 92.03 & 7.97 & 316 & 0.44 \\
$2002 / 2003$ & 73,758 & 90.91 & 9.09 & 323 & 0.44 \\
$2003 / 2004$ & 76,647 & 89.78 & 10.22 & 281 & 0.37 \\
$2004 / 2005$ & 82,677 & 85.59 & 14.3 & 183 & 0.22 \\
$2005 / 2006$ & 103,067 & 88.6 & 11.4 & 383 & 0.37 \\
$2006 / 2007$ & 115,720 & 88.4 & 11.6 & 215 & 0.18 \\
Total & 524328 & 89.2 & 10.8 & 1701 & 0.33 \\
\hline \hline
\end{tabular}




Table 2. Seroprevalence of HIV among blood donors in the CBTS data
\begin{tabular}{|llll|}
\hline Year & Total donors & HIV Seropositive & Seroprevalence (\%) \\
\hline $2001 / 2002$ & 28,991 & 183 & 0.63 \\
$2002 / 2003$ & 31,229 & 185 & 0.6 \\
$2003 / 2004$ & 30,054 & 150 & 0.5 \\
$2004 / 2005$ & 31,293 & 87 & 0.27 \\
$2005 / 2006$ & 35,347 & 106 & 0.29 \\
$2006 / 2007$ & 43,759 & 72 & 0.16 \\
Total & 200673 & 783 & 0.4 \\
\hline \hline
\end{tabular}

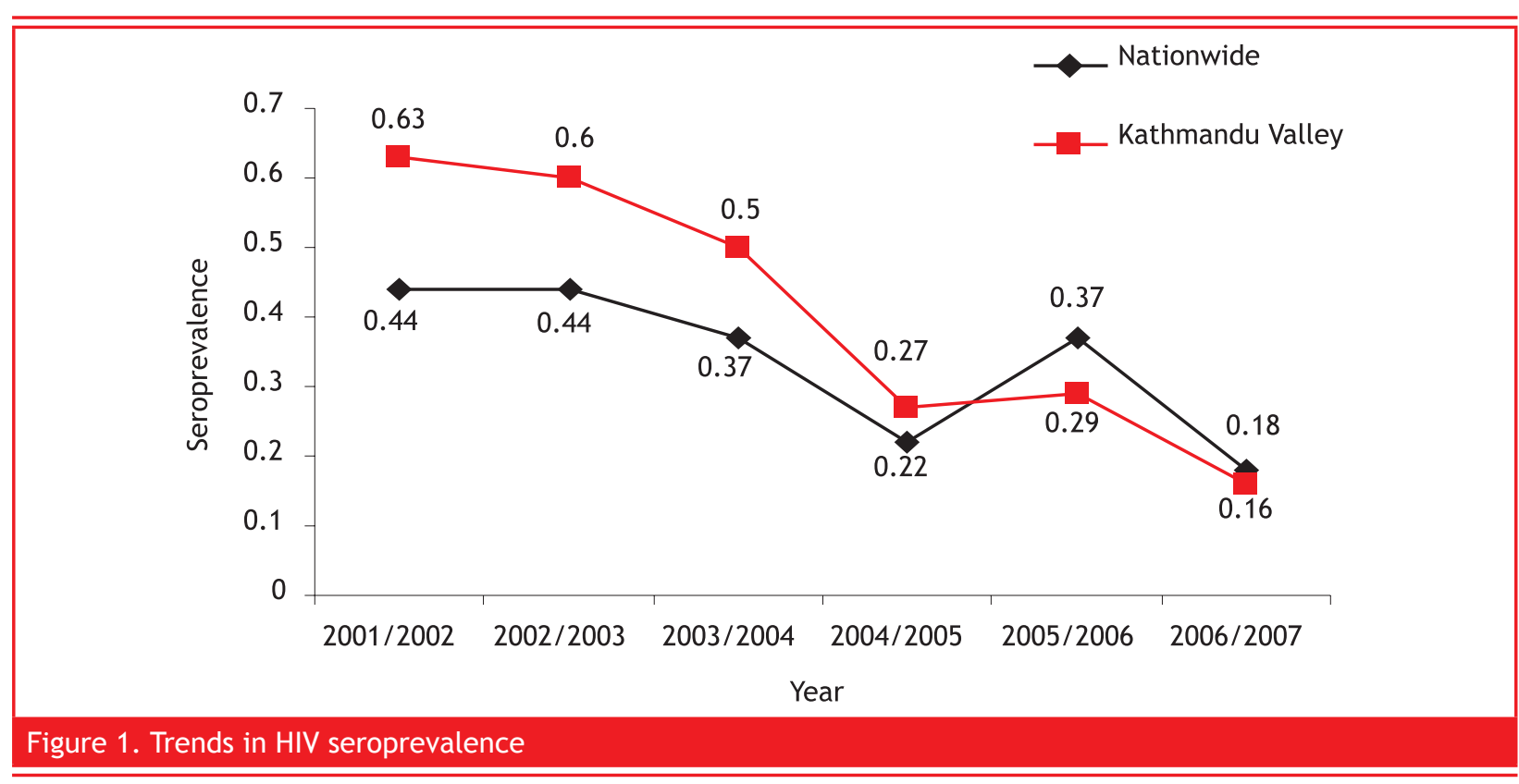

Table 3. Multiple pairwise comparisons for testing significance of difference in HIV Seroprevalence rates.

For CBTS, Kathmandu

Pair (Years)

2001/2002, 2004/2005

$2001 / 2002,2005 / 2006$

2001/2002, 2006/2007

2002/2003, 2004/2005

2002/2003, 2005/2006

2002/2003, 2006/2007

2003/2004, 2004/2005

2003/2004, 2005/2006

2003/2004, 2006/2007

2004/2005, 2006/2007

2005/2006, 2006/2002

For Nationwide

\begin{tabular}{lllll} 
Rates per 1000 & P-value & Pair (Years) & Rates per 1000 & P-value \\
\hline $6.3,2.8$ & $<0.001$ & $2001 / 2002,2004 / 2005$ & $4.4,2.2$ & $<0.001$ \\
$6.3,3.0$ & $<0.001$ & $2001 / 2002,2006 / 2007$ & $4.4,1.9$ & $<0.001$ \\
$6.3,1.6$ & $<0.001$ & $2002 / 2003,2003 / 2004$ & $4.4,2.2$ & $<0.001$ \\
$5.9,2.8$ & $<0.001$ & $2002 / 2003,2006 / 2007$ & $4.4,1.9$ & $<0.001$ \\
$5.9,3.0$ & $<0.001$ & $2003 / 2004,2004 / 2005$ & $3.7,2.2$ & $<0.001$ \\
$5.9,1.6$ & $<0.001$ & $2003 / 2004,2006 / 2007$ & $3.7,1.9$ & $<0.001$ \\
$5.0,2.8$ & $<0.001$ & $2004 / 2005,2005 / 2006$ & $2.2,3.7$ & $<0.001$ \\
$5.0,3.0$ & $<0.001$ & $2005 / 2006,2006 / 2007$ & $3.7,1.9$ & $<0.001$ \\
$5.0,1.6$ & $<0.001$ & & & \\
$2.8,1.6$ & $<0.001$ & & & \\
$3.0,1.6$ & $<0.001$ & & & \\
\hline
\end{tabular}




\section{DISCUSSION}

The overall seroprevalence of HIV among the blood donors significantly decreased from $0.44 \%$ to $0.18 \%$ in nationwide and $0.63 \%$ to $0.16 \%$ in CBTS, Kathmandu between 2001/2002 to 2006/2007. The decline in HIV seroprevalence rates might be due to the cumulative effect of increasing public awareness about HIV, implementation of stringent donor selection by blood transfusion services, self-deferral by high risk individuals and increased detection of HIV positive cases due to increased accessibility to HIV testing services like voluntary counselling and testing (VCT). The blood donors are the adult population within the age groups of 18-60 years, so prevalence in other age groups is missed in such studies, however it is generally accepted that the prevalence in the blood donors if interpreted cautiously can provide insight to the epidemic condition in general population. In the nationwide analysis, a significant increase in the seroprevalence rate was seen in the year 2005/2006 and importantly this is the year which experienced the first abrupt increase in the demand of blood and blood products (Table 1). Slightly higher seroprevalence rate was observed in the urbanized setting of Kathmandu Valley $(0.4 \%)$, which alone experienced about $40 \%$ of the total demand of blood supply in the country during the study period. The rate of decrease of seroprevalence in the Kathmandu Valley was relatively higher ( 0.039 percent per year) than in Nationwide $(0.024$ percent per year).

Similar to our study, a statistically non significant decreasing trend in HIV seroprevalence among blood donors was reported from New Delhi, India through the year 2002 to 2005 and the overall seroprevalence was also fairly higher than in Nepal. ${ }^{14}$ Totally in contrast to our study, a significantly increasing trend in HIV seroprevalence among blood donors was reported from the African country, Mali. ${ }^{15}$ The overall seroprevalence of HIV among Nepalese blood donors during the period of past six years estimated in this study was similar to the data reported from various cities in the neighboring country India. ${ }^{16-18}$ Much higher seroprevalence of HIV among blood donors than observed in present study has been reported from African countries. ${ }^{19-23}$ The overall seroprevalence of HIV among blood donors as revealed by this study was quite higher than reported in other studies among blood donors by Gupta et al. in Ludhiana of India, Rahaman et al. in Pakistan, Kakepoto et al. in Pakistan. ${ }^{24-26}$ Such differences in seroprevalence rate might be due to geographical variation, condition of epidemic, donor selection criteria and by performance characteristics of test kits as well as diagnostic algorithms used in each study.

\section{CONCLUSION}

The analysis of trends in HIV seroprevalence among blood donors through the year 2001- 2007 showed a significantly decreasing trend, both in nationwide and CBTS data. The decreasing trends might be due to the cumulative effect of increasing awareness of HIV and implementation of improved screening system for safe blood collection.

\section{ACKNOWLEDGEMENT}

The authors would like to acknowledge Nepal Red Cross Society, Central Blood Transfusion Service for its support to conduct this study.

\section{REFERENCES}

1. UNAIDS. 2007 AIDS epidemic update. [Online]. 2007 [cited 2008 Feb 3]. Available from: URL:http://www.unaids.org/en/ KnowledgeCentre/HIVData/EpiUpdate/EpiUpdArchive/2007/ default.asp

2. Gurubacharya VL, Rana T, Subedi BK. Profile of AIDS cases in Nepal. JNMA 1994;31:337-9.

3. NCASC. Cumulative HIV and AIDS situation of Nepal. Nepal: NCASC; 2007.

4. UNDP - You and Aids. The HIV portal for South Asia-Nepal at a glance. 2005 [Cited 2007 Jun 10]. Available from: URL:http:// www.youandaids.org/Asia\%20Pacific\%20at\%20a\%20Glance/ Nepal/

5. UNAIDS. Epidemiological fact sheets. Geneva: UNAIDS; 2002.

6. Chander A, Pawaha VK. Seroprevalence of HIV-1/HIV-2 Infection in Bhairahawa, Western Nepal - A Hospital Based Study. J Nep Health Research Council 2004; 2:51-4.

7. National Center for AIDS and STD control. Situation Analysis of HIV/AIDS in Nepal. Final Report. Kathmandu: National Center for AIDS and STD control; 2000.

8. Seddon D. HIV-AIDS in Nepal: The coming crisis. Bull Concern Asian Sch 1998; 30:35-45.

9. Singh S, Mills E, Honeyman S, Suvedi BK, Pant NP. HIV in Nepal: Is the Violent Conflict Fuelling the Epidemic? PLoS Med 2005;2:216.

10. Family Health International. Behavioral surveillance survey in the highway route of Nepal. 2000 [cited 2008 March 11]. Available from: URL:http://www.fhi.org/en/HIVAIDS/pub/ survreports/sexworkersnepal.htm

11. Family Health International. STD and HIV prevalence survey among female sex workers and truckers on highway routes in the Terai. 2000 cited 2008 March 11]. Available from: URL:http:// www.fhi.org/en/HIVAIDS/pub/survreports/nepalstdprev.htm

12. Silverman JG, Decker MR, Gupta J, Maheswari A, Willis BM, Raj A. HIV Prevalence and Predictors of Infection in Sex-Trafficked Nepalese Girls and Women. JAMA 2007;298:536-42.

13. Poudel KC, Okumura J, Sherchand JB, Jimba M, Murakami I, 
Wakai S. Mumbai disease in far western Nepal: HIV infection and Syphilis among male migrant returnees and non migrants. Trop Med Int Health 2003;8:933-9.

14. Pahuja S, Sharam M, Baitha B, Jain M. Prevalence and trends of markers of Hepatitis $\mathrm{C}$ virus, Hepatitis $\mathrm{B}$ virus and Human Immunodeficiency Virus in Delhi blood donors: a hospital based study. Jpn J Infect Dis 2007;60:389-91.

15. Tounkara A, Noumsi TG, Hengel RL. Increasing numbers of HIV infected blood donors reveal an expanding HIV-1 epidemic in Bamako, Mali. Int Conf Aids 2004;15.

16. Kaur H, Dhanoa J, Pawar G. Hepatitis C infection amongst blood donors in Punjab- a six year study. Indian J Hematol Blood Transfn 2001;19:21-2.

17. Mathai J, Sulochana PV, Satyabhama S, Nair PK, Sivakumar S. Profile of Transfusion Transmissible Infections and associated risk factors among blood donors of Kerala. Ind J Pathol Microbiol 2002;45:319-22.

18. Dey SK, Pal NK, Barat PK, De SK. Seroprevalence of HBV, HCV and HIV among blood donors in and around Calcutta (Kolkata), State West Bengal, India. International Conference on AIDS. Int Conf AIDS. 2002 Jul 7-12; 14: abstract no. WePeB6021.

19. Ampofo W, Nii-Treb N, Ansah J, Abe K, Naito H, Aidoo S, et al. Prevalence of blood-borne infectious diseases in blood donors in Ghana. J Clin Microbiol 2002; 40:3523-5.
20. Matee MI, Lyamuya EF, Mbena EC, Magessa PM, Sufi J, Marwa GJ, et al. Prevalence of transfusion-associated viral infections and syphilis among blood donors in Muhimbili Medical Centre in Dar es Salaam, Tanzania. East Afr Med J 1999;76:167-71.

21. Mwangi JW. Viral markers in blood donor population. East Afr Med J 1999;76: 35-7.

22. Sarkodie F, Adarkwa M, Adu-SarkodieY, Candotti D, Acheampong JW, Allain JP. Screening for viral markers in Volunteer and Replacement blood donors in West Africa. Vox Sang 2001;80:1427.

23. Rukundo H, Tumwesigye N, Wakwe VC. Screening for HIV1 through the regional blood transfusion service in SouthwestUganda: the Mbarara experience. Health Trasit 1997;7:101-4.

24. Gupta N, KumarV, Kaur A. Seroprevalence of HIV, HBV, HCV and syphilis in voluntary blood donors. Indian J Med Sci 2004;58:2557.

25. Rahman M, Akhtar G, Lodhi Y. Seroprevalence of Hepatitis C antibodies in blood donors. Pak J Med Sci 2002;18:193-6.

26. Kakepoto GN, Bhally HS, Khaliq G. Epidemiology of blood borne viruses. A study of healthy blood donors in Southern Pakistan. Southeast Asian JTrop Med Public Health 1996;27:703-12. 